\title{
Appraising the Effectiveness of a Simple Evaluational Approach to Problems of Retardation and Behavior in Childhood
}

\author{
WARREN KLEINBERG, M.D.. * PATRICIA A. O'CONNOR, M.D., M.P.H. $\dagger$
}

\begin{abstract}
$\mathrm{M}$ voted to the psychosocial disabilities in chil dren can be found in schools, speech clinics, rehabilitation centers, child guidance clinics, mental retardation clinics, and pediatric clinics. A complete team, as does exist in some teaching and demonstration centers, may consist of a psychologist, educational consultant, occupational therapist, physical therapist, speech therapist, audiologist, public health nurse, social worker, pediatrician, pediatric neurologist, psychiatrist, ophthalmologist and perhaps otologist. In some centers each child may be seen by nearly all of these specialists. On the other hand, as Grossman has noted, it is neither feasible nor necessary to refer every child with suspected retardation to a diagnostic evaluation center where a team gives comprehensive diagnostic evaluation. ${ }^{1}$
\end{abstract}

\section{Program Description}

At the University of Michigan Medical Center we see eight to 12 children every month who are referred for a general pediatric and psychologic evaluation because of a primary diagnosis of a learning, developmental or behavior disorder. The evaluation as we do it requires only one or two visits to the clinic, and patient contact is usually

* Fellow in Community Pediatrics, University of Michigan School of Public Health and the Department of Pediatrics and Communicable Diseases, Pediatric Outpatient Department, University of Michigan Medical Center.

+ Associate professor of Pediatrics and Communicable Diseases and of Maternal and Child Health, University of Michigan Medical Center, Ann Arbor, Michigan 48104 . limited to the pediatrician and the psychologist, though the clinic social worker may interview some parents. The evaluation consists of a standard history and physical examination and a standard psychologic evaluation utilizing diagnostic tests (Wisconsin, StanfordBinet, Cattel, Peabody, Leiter, Vineland and others) appropriate to the patient. A basic pediatrician-psychologist team is utilized in this clinic for the initial evaluation. The usual outcome of the evaluation is a set of recommendations to schools or referrals to agencies or clinics closer to the patient's home for the purpose of longitudinal counselling and remedial programs.

The clinic pediatricians are familiar with psychosocial problems. Ongoing patientoriented conferences are held frequently which include them, the psychologists, social workers, and one or more psychiatrists. A social worker and a child psychiatrist are readily available for consultation. Additional consultants are available, if needed, in pediatric neurology, psychiatry, rehabilitation, otology, speech pathology, ophthalmology and orthopedics.

In the evaluation we attempt to find and define any organic, and especially neurologic, defects; the parental hopes and expectations; the psychosocial status of the family; emotional factors interfering with the child's performance; intellectual capacity; and pertinent social, educational, and environmental factors in the community. We are cognizant of the need to correlate individual family needs and attitudes with available services. ${ }^{2}$ As Fremont has pointed out, the "consultant must 


\section{KLEINBERG AND O'CONNOR}

TABLE 1. Agreement Between Charted Recommendations and Parent's Responses

\begin{tabular}{|c|c|c|c|}
\hline $\begin{array}{c}\text { Recommendations } \\
\text { Noted on Charts }\end{array}$ & $\begin{array}{l}\text { No. Times } \\
\text { Recommen- } \\
\text { dation } \\
\text { Noted on } \\
\text { Record }\end{array}$ & $\begin{array}{l}\text { No. Times } \\
\text { Parent's } \\
\text { Responses } \\
\text { Corre- } \\
\text { sponded } \\
\text { to Charted } \\
\text { Recom- } \\
\text { mend. }\end{array}$ & $\begin{array}{l}\text { Responses } \\
\text { Recalled } \\
\text { by Parents } \\
\text { but not } \\
\text { Noted on } \\
\text { Chart }\end{array}$ \\
\hline $\begin{array}{l}\text { Child guidance } \\
\text { clinic }\end{array}$ & 6 & 6 & - \\
\hline $\begin{array}{l}\text { Psychiatric } \\
\text { counselling }\end{array}$ & 2 & 0 & - \\
\hline $\begin{array}{l}\text { Family service } \\
\text { agency }\end{array}$ & 4 & 4 & - \\
\hline Special education & 10 & 9 & - \\
\hline Special tutoring & 2 & 1 & - \\
\hline Speech therapy & 3 & 3 & - \\
\hline $\begin{array}{l}\text { Firmer discipline } \\
\text { for child }\end{array}$ & 1 & 1 & 1 \\
\hline $\begin{array}{l}\text { Less pressure on } \\
\text { child }\end{array}$ & 4 & 3 & 1 \\
\hline $\begin{array}{l}\text { Encourage child to } \\
\text { talk about feelings }\end{array}$ & 4 & 3 & - \\
\hline $\begin{array}{l}\text { No recommendations } \\
\text { (reassurance) }\end{array}$ & 1 & 1 & - \\
\hline $\begin{array}{l}\text { Return for re- } \\
\text { evaluation }\end{array}$ & 7 & 5 & 2 \\
\hline $\begin{array}{l}\text { Institutionalization } \\
\text { or special schooling } \\
\text { away from home }\end{array}$ & 2 & 2 & 2 \\
\hline
\end{tabular}

know the characteristics of the organization or person he is to deal with." 3 Local professional workers, who can provide continued guidance, counselling and support for parents are particularly important, and we try to identify such persons and encourage parents to seek their help. Until such contacts are established, the pediatrician, the psychologist, or the social worker acts as counsel and ad. vocate for the patient and family. The use of a pediatrician or a psychologist as an advocate is controversial but accepted,4,5 and is further encouraged by the results of this study.

\section{Approach to Evaluation}

The effectiveness of any evaluation team dealing with childhood psychosocial disorders is difficult to measure. With most cases there are no absolute or "unchallenged criteria for evaluating accuracy of diagnosis. Likewise, there is no uniform agreement about the comparative effectiveness of various therapy programs.

Despite these difficulties, we were desirous of appraising the long-range usefulness of the evaluations by our pattern of procedure. Accordingly we carried out a questionnaire survey. This (1) compared the extent to which parents understood and followed through on the recommendations which were noted in the patient's chart; and also (2) asked the parents for comments concerning their satisfaction or dissatisfaction with the evaluation process. Children having such additional handicapping conditions as heart disease, hydrocephalus and malformations were excluded from the survey.

Twenty cases whose initial evaluations had been made in February and March 1970 were reviewed one year later. The questions asked of the parents or guardians were: (l) What recommendations had we made? (2) Were the recommended services available? (3) Were they (the parents) able to find interested professionals to assist them locally? (4) Were the recommendations and the services obtained satisfactory? (5) Who made the initial referral to the clinic? Thirteen of the mailed questionnaires were returned, six others were responded to via telephone contacts, and one family was lost to follow-up.

Eleven of the patients had been referred because of behavior problems, seven for suspected mental retardation, and two for speech difficulties. Their ages at the evaluations ranged from 1-1/2 to $14-1 / 2$ years; six were preschoolers.

\section{Results}

The table shows what the parents remembered compared with the recommendations which had been recorded in the clinic record. All but two of the parents or guardians reported they were satisfied with the recommendations. With one of the two dissatisfied cases, the parents responded that institutionalization was recommended, but that they had worked intensively with the child at home and had obtained special education 


\section{APPROACH TO RETARDATION AND BEHAVIOR PROBLEMS}

classes for her (according to the clinic record, only family counselling and special education classes had been recommended). With the other case, psychiatric and family counselling had been recommended after a pathologic mother-son relationship had been found, but the mother's response mentioned no recommendations and stated that her son had been placed in a boarding school (it was apparent from the questionnaire and a telephone interview that the mother had been seeking a medical basis for her son's emotional problem). A third set of parents were dissatisfied with the services only because they seemed to be limited.

Eight referrals to the clinic were made by a family physician, six by the parents themselves, two by a nurse and teacher jointly, one by a nurse and a sacial worker jointly and one by a nurse.

Additional consultation was sought for two of the 19 patients surveyed. One child was referred to ophthalmology, where the need for corrective lenses was found, and the other was referred to pediatric neurology where hypotonia was confirmed.

\section{Conclusion}

In this limited sample the parents' responses corresponded very closely to the recorded recommendations and the parents generally seemed satisfied with the evaluations. This result is encouraging, in light of previous reports of parental dissatisfaction and lack of compliance. ${ }^{6, ?}$

We have found that a clinical pediatrician and a clinical psychologist have served adequately as the evaluation team for psychosocial referrals to this clinic. In view of the availability and accessibility of consultative medical services and of good community based programs, it seems unnecessary to duplicate these services in this clinic.

\section{References}

1. Grossman, H. J.: Symposium on mental retardation. Foreword. Pediatr. Clin. North Am. 15: 819, 1968.

2. Metheny, A. D. and Vernick, J.: Parents of the mentally retarded child: emotionally over. whelmed or informationally deprived $J$. Pediatr. 74: 953, 1969.

3. Fremont, A. C.: Utilization of community services. Pediatr. Clin. North Am. 15: 989, 1968.

4. Ackerly, W.: Utilization of a pediatrician in a community child guidance clinic I. low in. come community. Pediatrics 46: 803, 1970.

5. A.A.P. Committee on Children with Handicaps: The pediatrician and the child with mental retardation. A.A.P., Evanston, Ill., 1971.

6. Koch, R. J., Graliker, B. U., Sands, R. and Parmalee, A. H.: Evaluation of parental satisfaction with the medical care of a retarded child Pediatrics 23: 582, 1955.

7. Zuckerberg, H. D. and Snow, G. R.: What do parents expect from the physician? Pediatr. Clin. North Am. 15: 861, 1968.

\section{Editor's Note}

This paper by Kleinberg and O'Connor "Appraising the Effectiveness of a Simple Evaluational Approach to Problems of Retardation and Behavior in Childhood" was accepted for publication because it describes success with an emotional method of delivering this much needed aspect of pediatric health care. The real concern of this commentator is that the average pediatrician may surmise that with little difficulty he can duplicate the role of the authors; for unless he has been exposed to the psychologic and social aspects of pediatric practice during his early years of training and has kept his "hand in" by working with a multidisciplinary team, I fear that a pediatrician will not be able to function in the model here described. The point needing emphasis is that the training of pediatricians must be expanded to include a keen knowledge of the theoretical and technical roles played by the different professional members of a team. Unless these doctors know precisely how a physical therapist, occupational therapist, language therapist or special education specialist functions, they will not be able to assume the role when a problem arises which would ordinarily involve these professionals.

We agree that every referred case does not need a comprehensive evaluation by a sophisticated, multidisciplinary team. There is little question that a pediatrician who has been sensitized to the varieties of psychosocial ills, working together with a psychologist who knows how to use the "information processing 


\section{KLEINBERG AND O'CONNOR}

model," can make an effective screening team. By appropriate selection of consultations they can save many hours of professional time. By eliminating the numerous contacts made by the family in the multidisciplinary screening approach, they build up a closer rapport with the patient and parents much faster.

There are, nevertheless, other types of miniteam models which also can function effectively in screening for behavioral or learning problems. For instance, the occupational therapist and psychologist work well together in clarifying visual perceptually based learning disorders; the language therapist and social worker with language disorders; and the team of the physical therapist and social worker can do a superb job with a developmentally deviant infant. In these models the pediatrician, acting as a recipient of the information, can effectively translate the findings to parents-and help put the recommendations into action.

My thesis is that if the pediatrician is to serve as a central diagnostic figure for the rich diversity of these cases, he must have had the same exposure to skills assessment as therapists and teachers receive. $\mathrm{He}$ needs a special preparatory background. Furthermore, I find it difficult to agree that a family can get all the supportive help they need from one or two pediatric and psychologic discussions, in the absence of the feed-back provided by the social worker. Parents listen-but they often do not comprehend until after receiving repeated exposures to concepts.

These authors are in a situation where their superior training shows. That is why the model works for them. Can they describe for us their training curriculum?

If we could expand the clinical preparation of pediatricians to include an awareness of the total needs of families we could develop more efficient models of health service delivery. This is the message we hope the Kleinberg-O'Connor paper projects. Comments from our readers will be welcome.

Eric Denhoff, M.D. Providence, R. I.

\section{PRACTICAL POINTERS}

\section{FR'OM ENGLAND}

\section{The Predictive Developmental Assessment}

The pediatrician who is asked to assess babies for adoption must be honest with the adopting parents, and express doubts about the baby's development if doubts are felt. It is my practice in such cases to tell the adopting parents that the baby is at present a little below the average, but that one cannot be sure that he will not catch up and even prove to be above average in later years. Apparent retardation in an infant who has been in an institution may be due to emotional deprivation.

When an infant is definitely defective, one has to say so. No harm is done by underestimation; a mother who is told that a baby is just average, and who subsequently finds that he is a genius, is unlikely to be seriously annoyed. It is important, however, to prevent a foster parent from unknowingly adopting a mentally subnormal or spastic child.-R. S. ILLnvGwortu in Developmental Medicine and Child Neurology, December 1971.

\section{FROM AUSTRALIA}

\section{Congenital Laryngeal Stridor}

Fifty-one infants with noisy breathing due to a long relaxed epiglottis and aryepiglottic folds all had good physical and mental development. The stridor usually disappeared by two years of age. Respiratory function studies demonstrated a marked increase in inspiratory resistance before they ourgrew the obstructive symptoms.-P. D. Phelan et al., in Austral. Pediat. J., September 1971. 